\title{
Fertility Behaviour of Adolescent Mothers in Northern Nigeria and Neonatal Mortality Risk: Mediating Effect of Quality Maternal Health Services
}

\author{
Matthew A. Alabi, Motunrayo I. Fasasi and Mary O. Akanbi
}

\section{ABSTRACT}

Background: Despite rising prevalence of high-risk birth and adverse birth outcome among adolescent mothers in Nigeria, there is paucity of studies relating childhood mortality risk with fertility behaviour of adolescent mothers. This study examines fertility behaviour of adolescent mothers in northern Nigeria and neonatal mortality risk.

Methods: Data were derived by pooling together the three most recent Nigeria Demographic and Health Surveys (NDHS, 2008, 2013 and 2018). The sample size comprises of weighted sample of 3,739 adolescent mothers 15-19 years with 5, 274 live births for the period under consideration. Survival analysis (cox proportional hazard model) was used to estimate the hazard of neonatal mortality risk as a result of risky fertility behaviour.

Results: Quality of maternal health service utilization was poor among $\mathbf{7 3 . 0 \%}$ ) of the adolescent mothers. The independent effect of adolescent fertility behaviour revealed a rise in hazard for neonatal mortality, with increasing high risk fertility behaviour, single high-risk $(H R=2.69, p<0.001)$ and multiple high risk $(\mathrm{HR}=6.04, \mathrm{p}<0.001)$. Adjusting for quality of maternal health service utilization, resulted in reduced hazard for neonatal mortality, though the result did not reach statistical significance $(p>0.05)$. Adjusting for maternal, child characteristics and quality of maternal health service utilization, resulted in reduced hazard for neonatal mortality, though, the effect of risky fertility behaviour remained insignificant. Multiple birth babies were however, associated with elevated hazard for neonatal mortality $(H R=11.4, p<0.05)$ relative to single birth babies.

Conclusion: Adolescent fertility behaviour was associated with elevated hazard for neonatal mortality.

Keywords: Adolescent, fertility behaviour, adolescent mother, health service utilization, neonatal mortality, Nigeria.

\section{INTRODUCTION}

Globally, the population of young people is apparently rising, especially in developing countries. Young people aged 15-24 years accounts for $16.0 \%$ of the total world population [1]. More so, the demographics of most developing countries indicate adolescents and young people constitute significant proportion of their population. According to UNFPA, in seventeen developing countries, individuals under age 18 years accounts for at least half of its entire population. However, despite constituting substantial proportion of the population, majority of these young people are faced with barriers to development, making it difficult for them to fulfill their potentials, thereby undermining the prospects to achieving demographic
Published Online: November 13, 2020

ISSN: 2593-8339

DOI: $10.24018 /$ ejmed.2020.2.6.514

Matthew A. Alabi*

Academy for Health Development, Nigeria.

(e-mail: ayoalabi85@gmail.com)

Motunrayo I. Fasasi

Health Center, Obafemi Awolowo University, Nigeria.

Mary O. Akanbi

Academy for Health Development, Nigeria.

*Corresponding Author 
associated these adolescent births with adverse birth outcomes for the mother and risk of neonatal and infant death for the newborn [5]-[8].

Studies have offered possible explanations for these adverse birth outcomes and neonatal mortality risk among adolescent mothers. The higher likelihood of adolescent mothers having low birth weight babies is one of the explanations cited in literature [9]. Some other studies [10], [11] have reported adolescent mothers to be at increased risk of hypertension during pregnancy period. Another study [12] suggests poor birth outcomes among adolescent mothers to be linked with physiological immaturity among other factors.

Besides, recent childhood mortality indices showed Africa continues to account for greater burden of childhood mortality. Although few African countries such as Ethiopia and Egypt seem to be making appreciable progress in reducing childhood mortality, same cannot be said about Nigeria. Ethiopia and Egypt achieved $18.6 \%$ and $26.7 \%$ decline in Infant Mortality (IM) between 2011-2016 and 2009-2014 respectively during the five-year period preceding the most recent Demographic and Health Surveys [12], [13]. In contrast, Nigeria only achieved a $2.9 \%$ decline in IM for the five year period preceding the most recent 2018 Demographic and Health Survey. Also, while Egypt and Ethiopia achieved a decline in their childhood mortality, under-5 mortality in Nigeria increased from 128 to 132 deaths per 1,000 live births within the same period [14]. The above statistics indicate childhood mortality in Nigeria still remains a burden despite various interventions including implementation of programmed geared towards promoting higher proportion of childbirth receiving the attention of skilled health professional, increased immunization coverage among others [15].

Moreover, quality and use of maternal health services can help reduce the risk of maternal and childhood morbidity and mortality. Studies [16], [17] have shown the use of maternal health services to significantly help in moderating the adverse effect that might arise from pregnancy and child birth complications for the child and the mother. Yet, there exist dearth of research on risky fertility behaviour and neonatal mortality hazard especially among adolescent mothers in the northern part of the country. This is despite the fact that most of these girls are faced with poor socioeconomic status ranging from low level of school enrolment, residence in the poorest household wealth status with poor access and use of maternal health services.

Notwithstanding the fact that Nigeria has a relatively young population, with implication on sexual and reproductive health, available data indicates sexual and reproductive health indicators of the young people remains worrisome. With nearly half $(42.5 \%)$ of its population in the age group 10-14 years [18], they remained neglected in terms strategic, youth-oriented national sexual and reproductive policies and programmes which could have adverse effect on the country's prospect for sustainable development goal of achieving good wellbeing among its population. It is on this premise that this study, seeks to examine the fertility behaviour of adolescent mothers in northern Nigeria and neonatal mortality risk.

\section{A. Theoretical Framework}

\section{Mosley and Chen (1984)}

The theoretical framework underpinning this study is the Mosley and Chen childhood mortality framework [19]. This framework is applicable to this study, in addition to the fact that it has been widely applied in the study of childhood mortality in developing countries as a whole and Nigeria in particular. A study on contextual determinants of infant mortality in Nigeria, applied this theory [20]. The main thrust of this theory is that some sets of proximate factors were found to have a direct effect on childhood morbidity and mortality. However, this study will be adapting the maternal factors (one of the proximate determinants of childhood mortality) identified by the framework. These maternal factors are age at first birth, parity and birth interval. Consequently, risky fertility behaviour which is the principal explanatory variable (consisting of the Mosely and Chen maternal factors) was generated.

\section{MATERIAL AND METHODS}

\section{A. Data Source, Study Design and Study Population}

The study data were derived from the three most recent Nigeria Demographic and Health Surveys (NDHS, 2008, 2013 and 2018), pooled together to generate a single dataset. The NDHS is a nationally representative survey which collected data from a total sample size of $(2008=33$, $385),(2013=38,948)$ and $(2018=41,821)$ women age $15-49$ for the 2008, 2013and 2018 survey respectively. ICF International through the USAID-funded MEASURE DHS program provided technical and financial assistance for the survey designed to collect data on fertility, family planning and maternal and child health. The survey used crosssectional research design.

The study population comprised women in the child bearing years who had at least one live birth, five years period preceding the survey. Since the unit of analysis is neonatal mortality, the kids recode dataset was analyzed. The sample size comprises of a weighted sample of 3,739 adolescent mothers 15-19 years (pooled from the three datasets) with 5, 274 live births for the period under consideration. Owing to the complex nature of DHS design, the "svy" command was employed during analysis to adjust for clustering (enumeration areas) and sampling weight so as to ensure the data was nationally representative. Analysis was performed using the cox proportional hazard model (survival analysis). The choice of survival analysis was necessitated by the fact that the analytical interest is to study the time until an event occurs. The outcome variable was neonatal mortality, defined as occurring within the first 28 days of life. Deaths occurring after 28 days were excluded in the analysis.

\section{B. Sampling Technique}

A nationally representative sample was used for the 2008 , 2013 and 2018 NDHS, covering the whole population residing in non-institutional residence in the country. The sample frame used for the survey was the list of Enumeration Areas (EAs) originally prepared the National 
Population Commission for the 2006 Population Census of Nigeria. The sample design made provision for population and health indicators to be estimated at the national, regional and state levels. In addition, there was provision for computing indicators specific for the six regions of the country, 36 states and the Federal Capital Territory, Abuja. Administratively, Nigeria as a country is divided into states. Each state is further divided into Local Government Areas (LGAs), while each LGA is divided into localities. In addition to these administrative units, during the 2006 population census, each locality was subdivided into census enumeration areas.

The primary sampling unit (PSU), referred to as a cluster in the NDHS, is defined on the basis of EAs from the 2006 EA census frame. The sample was selected using a stratified three-stage cluster design in both rural and urban areas. Compete household listing was carried out including mapping exercise for each cluster, with the list of households serving as the sampling frame used for selecting the households. Households that were regular were all selected. Training was conducted for the NPC listing enumerators on the use of Global Positioning System (GPS) receivers for calculating coordinates of the sample clusters. The eligibility criteria for interview were all women of reproductive age 15-49 years who were either permanent residents of the households or visitors present in the households on the night before the survey.

\section{Statistical Analysis}

The study employed both univariate, bivariate, and multivariate analysis. Descriptive such as frequency count and percentages were performed at the univariate level. At the bivariate level, chi square test was performed to test for association between categorical variables. Only explanatory variables that were significantly associated with outcome variable were included into the multivariate model. The multivariate analysis involves performing survival analysis (cox proportional hazard model). The use of survival analysis was considered more appropriate since the outcome variable is a time to event variable i.e. age at birth and involves following the newborn from birth until time of death. The $0.05 \%$ alpha threshold was the acceptable level of significance for the study. Stata 14.0 was used in performing the analysis.

\section{Measurement of Variables}

The outcome variable is neonatal mortality, defined as death occurring within the first 28 days of life. The variable measuring age at death in the Nigeria Demographic and Health Survey dataset was used for the outcome variable (risk of neonatal mortality). This was however recoded by keeping for only deaths occurring within the first 28 days of life, while deaths after 28 days were right-censored. The principal explanatory variable was adolescent fertility behaviour. Adolescent fertility behaviour (proxy by risky fertility behaviour) was generated from the NDHS dataset as a single variable categorized into four, namely: no risk, unavoidable rick, single high-risk and multiple high-risk. According to DHS classification, the first category (no risk) comprises of women who are not at risk at all; the second category (unavoidable risk) is defined as women whose age at first birth is in the age range 18-34 years; the third category (single high-risk) is defined as women exposed to just one risk i.e. those whose age at first birth is either below 18 years, birth interval less than 24 months or birth order above 3; fourth category (multiple high-risk) is defined as women exposed to more than one risk i.e. combination of at least two single high risk.

Quality of maternal health service utilization was measured using antenatal attendance, number of antenatal visits, place of delivery, postnatal check for baby and mother. Postnatal check for baby after two months was excluded since the unit of analysis was neonatal mortality (death within 28 days). Mothers who utilize at least three of the maternal health services were classified as having good maternal health service utilization, otherwise categorized as poor. For instance, a woman who attended antenatal, had minimum of four visit, and deliver in a health facility was categorized as having good maternal health service utilization. Other explanatory variables used are: maternal education, defined as (no education, primary, secondary and higher), household wealth index derived using principal component analysis and categorized as poor, middle and rich. Place of residence (rural and urban), child's sex (male and female), birth type (single and multiple births), antenatal attendance (measured as attended antenatal, coded as 1 , Yes, otherwise no, coded 0 ) and place of delivery (whether delivery occurs in a health facility or outside health facility.

\section{E. Ethical Consideration}

Strict standards are usually maintained for protecting respondents of all DHS surveys. As a registered DHS dataset user, approval for the use of data set used for this study was sought and granted by the Demography and Health Survey (DHSP program). The Demography and Health Survey (DHS) program and ICF international: 530 Gaither Road, Suite 500, Rockville, MD 20850, USA.

\section{RESULTS}

\section{A. Univariate Analysis}

The socio-demographic characteristics of the women (table 1) indicates larger percentage $(40.4 \%)$ of the adolescent mothers were age 18 years, followed by age 19 years $(32.7 \%)$, while age 15 years accounted for the least proportion $(2.4 \%)$. Likewise, nearly three quarter $(73.7 \%)$ had no formal education; only (12.0\%) had secondary/higher education. Significant proportion $(86.6 \%)$ resides in rural area. The distribution of the adolescent mothers according to geopolitical zone indicates, higher proportions $(56.2 \%)$ were residing in the North-west region, followed by North-east $(29.0 \%)$ region. Majority $(88.1 \%)$ of the adolescent mothers were affiliated to Islam religion, while $(10.6 \%)$ practice Christianity. Women from the poorest household accounted for more than two thirds $(71.2 \%)$. Similarly, higher percentage $(45.7 \%)$ of the women had birth interval of 24-35 month, (49.5\%) attended antenatal care during pregnancy, while significant proportion (81.7) of the births occurred outside health facility. There was no postnatal check for $(85.2 \%)$ of the 
adolescent mothers after child delivery. Overall, the quality of maternal health service utilization of majority $(73.0 \%)$ of the adolescent mothers was poor. Considerable proportions $(98.9 \%)$ of the births were single birth, with sex of the child almost evenly distributed, male $(50.3 \%)$ and female $(49.7 \%)$. The trend in risky fertility behaviour suggest gradual decline $(36.5 \%)$ in 2008, (32.7\%) in 2013 and $(30.3 \%)$ in 2018 (Table 1).

TABLE 1: SOCIO-DEMOGRAPHIC CHARACTERISTICS

\begin{tabular}{|c|c|c|}
\hline Maternal Characteristics & {$[\mathrm{N}=3739]$} & $\%$ \\
\hline \multicolumn{3}{|l|}{ Age Group } \\
\hline 15years & 89 & 2.4 \\
\hline 16 years & 242 & 6.6 \\
\hline 17 years & 661 & 17.9 \\
\hline 18 years & 1490 & 40.4 \\
\hline 19 years & 1208 & 32.7 \\
\hline \multicolumn{3}{|l|}{ Level of Education } \\
\hline No formal education & 2754 & 73.7 \\
\hline Primary & 534 & 14.3 \\
\hline Secondary/higher & 451 & 12.0 \\
\hline \multicolumn{3}{|l|}{ Wealth Index } \\
\hline Poor & 2662 & 71.2 \\
\hline Middle & 683 & 18.3 \\
\hline Rich & 394 & 10.5 \\
\hline \multicolumn{3}{|l|}{ Region of Residence } \\
\hline North-Central & 553 & 14.8 \\
\hline North-East & 1084 & 29.0 \\
\hline North-West & 2102 & 56.2 \\
\hline \multicolumn{3}{|l|}{ Place of Residence } \\
\hline Urban & 501 & 13.4 \\
\hline Rural & 3237 & 86.6 \\
\hline \multicolumn{3}{|l|}{ Religion } \\
\hline Islam & 3,285 & 88.1 \\
\hline Christianity & 396 & 10.6 \\
\hline Others & 47 & 1.3 \\
\hline \multicolumn{3}{|l|}{ Exposure to mass media } \\
\hline Yes & 1593 & 42.6 \\
\hline No & 2146 & 57.4 \\
\hline \multicolumn{3}{|l|}{ CHILD'S } \\
\hline \multicolumn{3}{|l|}{ CHARACTERISTICS } \\
\hline \multicolumn{3}{|l|}{ Childs Sex } \\
\hline Male & 1879 & 50.3 \\
\hline Female & 1860 & 49.7 \\
\hline \multicolumn{3}{|l|}{ Birth Type } \\
\hline Single birth & 3700 & 98.9 \\
\hline Multiple birth & 39 & 1.1 \\
\hline
\end{tabular}

\section{B. Bivariate Analysis}

The result of the bivariate analysis revealed maternal characteristics were significantly associated with risky fertility behaviour (RSB). Poor socioeconomic characteristics were significantly associated with risky fertility behavior (table 3). For instance, RFB was more prevalent $\left(\chi^{2}=67.0, p<0.05\right)$ among adolescent mothers with no education $(80.0 \%)$ when compared to those with at least secondary education $(6.0 \%)$. Also, risky fertility behaviour was observed among nearly three quarter of the adolescent mothers $(72.0 \%)$ from the poorest household wealth index relative to $(10.0 \%)$ adolescent mothers from rich household wealth status $\left(\chi^{2}=34.2, \mathrm{p}<0.05\right)$. Similarly, the prevalence of risky fertility behaviour was highest among adolescent mothers from Northwest $(47.6 \%)$, followed by Northeast $(35.1 \%)$ and North central $(17.3 \%)$. Regional variation was statistically significant $\left(\chi^{2}=20.8, \mathrm{p}<0.05\right)$. Place of residence was significantly associated with risky fertility behaviour $\left(\chi^{2}=25.0, \quad \mathrm{p}<0.05\right)$ among adolescent mothers. Higher prevalence was found among adolescent mothers from the rural area $(86.8 \%)$ when compared to the urban area $(13.2 \%)$. Exposure to mass media also influenced risky fertility behaviour among the adolescent women $\left(\chi^{2}=12.3\right.$, $\mathrm{p}<0.05)$. Higher prevalence was found among adolescent mothers not exposed to social media (59.8\%). Other maternal characteristics that were significantly associated with risky fertility behaviour are ethnicity $\left(\chi^{2}=28.7, \mathrm{p}<0.05\right)$ and religion $\left(\chi^{2}=39.1, \mathrm{p}<0.05\right)$ (Table 2 and 3$)$.

TABLE 2: MATERNAL HEALTH-SEEKING BEHAVIOUR

\begin{tabular}{|c|c|c|}
\hline Maternal health seeking behaviour & Freq & $\%$ \\
\hline \multicolumn{3}{|l|}{ Antenatal Visit** } \\
\hline Yes & 1454 & 49.5 \\
\hline No & 1484 & 50.5 \\
\hline \multicolumn{3}{|l|}{ Number of antenatal visit** } \\
\hline Less than 4 visits & 539 & 37.1 \\
\hline At least four visits & 915 & 62.9 \\
\hline \multicolumn{3}{|l|}{ Others } \\
\hline \multicolumn{3}{|l|}{ Place of Delivery** } \\
\hline Non-health facility & 3040 & 81.7 \\
\hline Health facility & 683 & 18.3 \\
\hline \multicolumn{3}{|c|}{ Postnatal check for mother after delivery } \\
\hline Yes & 435 & 14.8 \\
\hline No & 2502 & 85.2 \\
\hline \multicolumn{3}{|l|}{ Postnatal check for baby } \\
\hline Yes & 347 & 12.3 \\
\hline No & 2483 & 87.7 \\
\hline \multicolumn{3}{|c|}{ Quality of maternal health service utilization } \\
\hline Good & 328 & 27.0 \\
\hline Poor & 889 & 73.0 \\
\hline \multicolumn{3}{|l|}{ FERTILITY BEHAVIOUR } \\
\hline \multicolumn{3}{|l|}{ Risky fertility behaviour } \\
\hline No Risk & 262 & 7.0 \\
\hline Unavoidable Risk & 456 & 12.2 \\
\hline Single High-risk & 2803 & 75.0 \\
\hline Multiple High-risk & 217 & 5.8 \\
\hline \multicolumn{3}{|l|}{ Birth Interval } \\
\hline$<24$ months & 313 & 38.0 \\
\hline 24-35 months & 376 & 45.7 \\
\hline $36+$ months & 134 & 16.3 \\
\hline
\end{tabular}

**Missing and non-response excluded in analysis.

\section{Multivariate Analysis}

Multivariate analysis involves performing cox proportional hazard model. Five models were presented (Table 4). The first model (unadjusted) examined the independent effect of risky fertility behaviour (RFB) on hazard of neonatal mortality. The result showed a rise in hazard for neonatal mortality with increasing risky fertility behaviour, single high-risk $(\mathrm{HR}=2.69, \mathrm{p}<0.001)$ and multiple high risk $(\mathrm{HR}=6.04, \mathrm{p}<0.001)$. Adjusting for maternal characteristics (model two), resulted in elevated neonatal mortality, single high-risk $(\mathrm{HR}=2.90, \mathrm{p}<0.001)$ and multiple high risk $(\mathrm{HR}=7.14, \mathrm{p}<0.001)$. Model three adjusted for quality of maternal health service utilization. The result revealed the effect of risky fertility behaviour on hazard of neonatal mortality became statistically insignificant. Furthermore, the fourth model (full model) adjusted for maternal, child characteristics and adequacy of maternal health service utilization. The result revealed reduced hazard for neonatal mortality. Also, the effect of risky fertility behaviour remained insignificant. Multiple birth babies were however, associated with elevated hazard for neonatal mortality $(\mathrm{HR}=12.1, \mathrm{p}<0.05)$ relative to single birth babies (Table 4). 
TABLE 3: RISKY FERTILITY BEHAVIOUR AND SOCIO-DEMOGRAPHIC CHARACTERISTICS

\begin{tabular}{|c|c|c|c|c|c|}
\hline Maternal Characteristics & No risk & $\begin{array}{c}\text { Unavoidable } \\
\text { risk }\end{array}$ & Single risk & Multiple risk & $\begin{array}{c}\chi^{2} \text { statistics } \\
{[\mathrm{N}=3,739]}\end{array}$ \\
\hline No formal education & $184(70.8)$ & $280(60.1)$ & $2009(73.2)$ & $176(80.0)$ & \\
\hline Primary & $41(15.8)$ & $71(15.2)$ & $396(14.4)$ & $31(14.1)$ & 67.0 \\
\hline Secondary/higher & $35(13.4)$ & $115(24.7)$ & $339(14.4)$ & $13(5.9$ & $(\mathrm{p}=0.001)$ \\
\hline \multicolumn{6}{|l|}{ Wealth Index } \\
\hline Poor & $163(62.2)$ & $283(62.1)$ & $2051(73.2)$ & $165(75.9)$ & \multirow{3}{*}{$34.23(\mathrm{p}=0.001$} \\
\hline Middle & $71(27.0)$ & $96(21.1)$ & $482(17.2)$ & $33(15.3)$ & \\
\hline Rich & $28(10.8)$ & $77(16.8)$ & $270(9.6)$ & $19(8.8)$ & \\
\hline \multicolumn{6}{|l|}{ Region of Residence } \\
\hline North-Central & $37(14.0)$ & $93(20.4)$ & $400(14.3)$ & $23(10.6)$ & \multirow{3}{*}{$20.81(\mathrm{p}=0.002)$} \\
\hline North-East & $72(27.5)$ & $131(28.8)$ & $805(28.7)$ & $75(34.4)$ & \\
\hline North-West & $153(58.5)$ & $231(50.8)$ & $1598(57.0)$ & $119(55.0)$ & \\
\hline \multicolumn{6}{|l|}{ Place of Residence } \\
\hline Urban & $38(14.7)$ & $91(20.0)$ & $345(12.3)$ & $27(12.3)$ & \multirow{2}{*}{$24.97(\mathrm{p}=0.001)$} \\
\hline Rural & $224(85.3)$ & $364(80.0)$ & $2459(87.7)$ & $191(87.7)$ & \\
\hline \multicolumn{6}{|l|}{ Exposure to mass media } \\
\hline Yes & $136(51.8)$ & $222(48.8)$ & $1153(41.1)$ & $81(37.3)$ & \multirow{2}{*}{$12.28(\mathrm{p}=0.001)$} \\
\hline No & $126(48.1)$ & $233(51.2)$ & $1650(58.9)$ & $136(62.7)$ & \\
\hline
\end{tabular}

TABLE 4: COX PROPORTIONAL HAZARD SHOWING THE INFLUENCE OF RISKY FERTILITY BEHAVIOUR ON NEONATAL MORTALITY RISK

\begin{tabular}{|c|c|c|c|c|c|c|c|c|}
\hline \multirow{2}{*}{$\begin{array}{l}\text { Explanatory variables } \\
\text { Risky Fertility }\end{array}$} & \multicolumn{2}{|c|}{$\begin{array}{l}\text { Model One: } \\
\text { Risky fertility behaviour }\end{array}$} & \multicolumn{2}{|c|}{$\begin{array}{c}\text { Model Two: } \\
\text { Maternal characteristics }\end{array}$} & \multicolumn{2}{|c|}{$\begin{array}{c}\text { Model Three: } \\
\text { adjusted for health } \\
\text { seeking behaviour }\end{array}$} & \multicolumn{2}{|c|}{$\begin{array}{l}\text { Model Four: } \\
\text { Full model }\end{array}$} \\
\hline & UHR & $95 \% \mathrm{CI}$ & AHR & $95 \% \mathrm{CI}$ & HR & $95 \% \mathrm{CI}$ & OR & $95 \% \mathrm{CI}$ \\
\hline No risk & 1.000 & & 1.000 & & 1.000 & & 1.000 & \\
\hline Unavoidable risk & 1.88 & $0.9-4.0$ & $2.31^{*}$ & $1.1-4.8$ & 1.49 & $0.5-4.0$ & 1.91 & $0.6-5.4$ \\
\hline Single High-Risk & $2.69 * *$ & $1.4-5.3$ & $2.90 * *$ & $1.5-5.6$ & 1.22 & $0.5-3.2$ & 1.16 & $0.4-3.1$ \\
\hline Multiple High-Risk & $6.04 * *$ & $2.6-13.8$ & $7.14 * *$ & $3.2-16.0$ & 1.64 & $0.3-9.0$ & 2.21 & $0.4-12.8$ \\
\hline \multicolumn{9}{|l|}{ Education Level } \\
\hline No formal education & & & 1.000 & & & & 1.000 & \\
\hline Primary & & & 1.34 & $0.9-1.9$ & & & 1.81 & $0.9-4.0$ \\
\hline Secondary & & & 0.61 & $0.3-1.0$ & & & 0.40 & $0.1-1.4$ \\
\hline \multicolumn{9}{|l|}{ Wealth Index } \\
\hline Poor & & & 1.000 & & & & 1.000 & \\
\hline Middle & & & 1.36 & $0.9-2.0$ & & & 1.41 & $0.7-2.7$ \\
\hline Rich & & & 1.07 & $0.6-1.9$ & & & 0.85 & $0.2-3.0$ \\
\hline \multicolumn{9}{|l|}{ Region of Residence } \\
\hline North-Central & & & 1.000 & & & & 1.000 & \\
\hline North-East & & & 1.11 & $0.7-1.8$ & & & 1.67 & $0.6-5.0$ \\
\hline North-West & & & 1.17 & $0.6-1.8$ & & & 2.47 & $0.9-6.7$ \\
\hline \multicolumn{9}{|l|}{ Media exposure } \\
\hline No & & & 1.000 & & & & & \\
\hline Yes & & & 0.90 & $0.4-1.8$ & & & & \\
\hline \multicolumn{9}{|l|}{ Place of Residence } \\
\hline Urban & & & 1.000 & & & & 1.000 & \\
\hline Rural & & & 0.91 & $0.6-1.4$ & & & 1.11 & $0.5-2.4$ \\
\hline \multicolumn{9}{|l|}{ Child's sex } \\
\hline Male & & & 1.000 & & & & 1.000 & \\
\hline Female & & & 0.82 & $0.6-1.1$ & & & 0.84 & $0.4-1.7$ \\
\hline \multicolumn{9}{|l|}{ Birth Type } \\
\hline Single birth & & & 1.000 & & & & 1.000 & \\
\hline Multiple birth & & & $8.15 * *$ & $4.5-14.7$ & & & $11.37^{*}$ & $3.8-34.3$ \\
\hline \multicolumn{9}{|c|}{$\begin{array}{l}\text { Adequacy of maternal } \\
\text { health service utilization }\end{array}$} \\
\hline Inadequate & & & & & 1.000 & & 1.000 & \\
\hline Adequate & & & & & 1.03 & $0.4-1.5$ & 1.26 & $0.6-2.7$ \\
\hline
\end{tabular}

UHR=Unadjusted Hazard Ratio, AHR=Adjusted Hazard Ratio, CI=Confidence Interval.

\section{DisCUSSION AND CONCLUSION}

The study lends credence to Mosley and Chen framework of childhood mortality, with regards to the effect of maternal characteristics namely age at first birth, parity, and birth internal on childhood mortality. Since adolescent births are largely regarded as high risk, the poor socioeconomic status of these adolescent mothers, in addition to the poor maternal health service utilization that could have helped in mitigating the negative effect of this risky fertility behaviour on neonatal mortality risk calls for serious attention. The quality of maternal health service utilization was poor among the adolescent mothers. This study found risky fertility behaviour was independently associated with elevated risk for neonatal mortality. A recent study on high risk pregnancies and factors associated with neonatal mortality found newborn baby of women with high-risk pregnancies were at risk of neonatal mortality [21]. Also, a review of young maternal age at birth and risk of neonatal death, using data from Demographic and Health Surveys of 45 middle and low income countries found that regardless of the region, risk of death was reportedly higher among younger mothers below age 16 years [22]. Previous 
studies [23], [24] have also reported young maternal age to be independently associated with adverse birth outcome. However, the effect became insignificant after adjusting for maternal, child characteristics and quality of maternal healthcare utilization.

These studies reported poor socioeconomic status namely poverty, low educational status, inadequate prenatal care and being unmarried were reported to be prevalent among adolescent mothers and can therefore enhanced the adverse birth outcomes. This study also found the socioeconomic status of the adolescent mothers to be poor. For instance, nearly three quarter of the adolescent mothers had no formal education, belonged to the poorest household wealth status and resides in rural area. Moreover, some researchers have argued that with adequate prenatal care, pregnancy among adolescent mothers will not necessarily pose any risk [25], [26].

In our study, even after adjusting for maternal socioeconomic, demographic attributes and health service utilization, the direction of risk of neonatal death among the adolescent mothers did not vary. Lowest risk was however, reported among adolescent mothers with first birth. In this study the effect of adolescent fertility behaviour on neonatal mortality risk was similar with previous models focusing on adverse birth outcomes after adjusting for maternal socioeconomic characteristics and other health and behavioural factors. Therefore, appropriate interventions can target improving the poor maternal socioeconomic status of adolescent mothers in addition to removing socio-cultural barriers impeding access to quality maternal health service utilization especially among adolescent mothers in low income countries such as Nigeria.

\section{ACKNOWLEDGMENT}

The author would like to express his profound gratitude to ICF Macro, Calverton USA which collected the original data used in this study and also granted access to the data via the DHS archive.

\section{REFERENCES}

[1] United Nations, World Population Prospects 2017, available from https:// population. un. org/wpp /D ownload/Standard/Population/.

[2] UNFPA (2014): State of the World Population. The Power of 1.8 Billion, Adolescent Youth and the Transformation of the future.

[3] S. Neal, Z. Matthews, M. Frost, H. Fogstad, A.V. Camacho, L. Laski (2012). Childbearing in adolescents aged 12-15 years in low resource countries: a neglected issue. New estimates from demographic and household surveys in 42 countries. Acta Obstet Gynecol Scand; 91(9):1114-8. pmid:22620274.

[4] WHO Adolescent pregnancy. World Health Organization; [cited 2015 Jul 15]; http://www. who.int/ mediacentre/factsheets/fs364/en/.

[5] A. Glassman, R. Silverman, K. McQueston (2012). Adolescent Fertility in Low- and Middle-Income Countries: Effects and Solutions. Cent Glob Dev Work Pap No 295.

[6] N. Kozuki, A.C.C. Lee, M.F. Silveira, A. Sania, J.P. Vogel, L. Adair, et al. (2013). The associations of parity and maternal age with smallfor-gestational-age, preterm, and neonatal and infant mortality: a meta-analysis. BMC Public Health;13 Suppl 3: S2.

[7] Y. Mekonnen, B. Tensou, D.S. Telake D, T. Degefie, A. Bekele (2013). Neonatal mortality in Ethiopia: trends and determinants. BMC Public Health;13(1]:483.

[8] UNICEF (2011). The state of the world's children 2011. Adolescence: An age of opportunity. New York: UNICEF.
[9] Chen X-K., Wen S.W., Fleming N., Yang Q., Walker M.C. (2008) Increased risks of neonatal and postneonatal mortality associated with teenage pregnancy had different explanations. J Clin Epidemiol Elsevier; 61 (7):688-94.

[10] A.C. Granja, F. Machungo, A. Gomes, S. Bergström (2001) Adolescent maternal mortality in Mozambique. $J$ Adolesc Heal;28(4):303-6.

[11] B.O. Okusanya, E.O. Aigere, A. Abe, H.M. Ibrahim, R.A. Salawu (2013). Maternal deaths: initial report of an on-going monitoring of maternal deaths at the Federal Medical Centre Katsina, Northwest Nigeria. J Matern Fetal Neonatal Med;26(9):885-8. pmid:23311885.

[12] A.M. Fraser, J.E. Brockert, R.H. Ward (1995). Association of young maternal age with adverse reproductive outcomes. The New England Journal of Medicine. Vol. 332 p. 1113-7.

[13] Central Statistical Agency (CSA) [Ethipia] and ICF, 2016. Ethiopia Demography and Health Survey 2016, Addis Ababa, Ethiopia and Rockville, Maryland, USA: CSA and ICF.

[14] Ministry of Health and Population [Egypt], El-Zanaty and Associates [Egypt], and ICF International, 2015. Egypt Demographic and Health Survey, 2014. Cairo, Egypt and Rockville, Maryland, USA: Ministry of Health and Population and ICF International.

[15] National Population Commission (NPC) [Nigeria] and ICF. 2019 Nigeria Demographic and Health Survey 2018 Key Indicators Report. Abuja, Nigeria, and Rockville, Maryland, USA: NPC and ICF.

[16] Ochako, R., Fotso, C.J, Ikamari, L. and Khasakhala, A. 2011. Utilization of maternal health services among young women in Kenya: Insights from the Kenya Demographic and Health Survey, 2003. BMC Pregnancy and Childbirth, 11:1.

[17] R. Nigatu, (2012): Infant mortality in the rural Sidama zone, southern Ethiopia: examining the contribution of key pregnancy and postnatal health care services.

[18] The World Factbook - Central Intelligence Agency". www.cia.gov. Retrieved 10 April 2018

[19] W.H. Mosley, and L.C. Chen (1984). An analytical framework for the study of child survival in developing countries, Population and development review 10:25-45.

[20] S.A. Adedini, (2013). Contextual Determinants of Infant and Child Mortality in Nigeria, University of Witwatersrand, Johannesburg, SA, $\mathrm{PhD}$ Thesis.

[21] M.D. Demitto, A.A. Gravena, C.M. Dell'Agnolo, M.B. Antunes, \& S.M. Pelloso, (2017). High risk pregnancies and factors associated with neonatal death. Revista da Escola de Enfermagem da USP, 51.

[22] S. Neal, A.A. Channon, \& J. Chintsanya, (2018). The impact of young maternal age at birth on neonatal mortality: Evidence from 45 low and middle income countries. PloS one, 13(5), e0195731.

[23] M.M. Rogers, M.D. Peoples-Sheps, \& C. Suchindran, C. (1996). Impact of a social support program on teenage prenatal care use and pregnancy outcomes. Journal of Adolescent Health, 19(2), 132-140.

[24] J. Brooks-Gunn, \& G.J. Duncan, (1997). The effects of poverty on children. The future of children, 55-71.

[25] D. Liran, I.S. Vardi, R. Sergienko, \& E. Sheiner, (2013). Adverse perinatal outcome in teenage pregnancies: is it all due to lack of prenatal care and ethnicity? The Journal of Maternal-Fetal \& Neonatal Medicine, 26(5), 469-472.

[26] A.A. Mahfouz, M.M. El-Said, R.A. Al-Erian, \& A.M. Hamid (1995). Teenage pregnancy: are teenagers a high risk group? European Journal of Obstetrics \& Gynecology and Reproductive Biology, 59(1), 17-20.

Fasasi M. I., PhD is the Chief Nursing Officer at the Health Centre, Obafemi Awolowo University, Ile-Ife, Nigeria. Her research area is in Health Psychology, with interest in Violence among couples.

Alabi M. A., MSc is a Demographer and Statistician, currently the Programme and Research Manager at the Academy for Health Development, Ile-Ife, Nigeria. His research area is in Maternal and Child Health. He is interested in investigating causes of death during childhood period and implication of high risk births on maternal and child health.

Akanbi M. O. is a Social Researcher with specialization in Social Work and currently works with the Academy for Health Development, Ile-Ife, Nigeria. Her research interest includes studies on gender and violence against women. 